\title{
AS GRAVURAS RUPESTRES DA ÁREA ARQUEOLÓGICA DO SERIDÓ, NO ESTADO DO RIO GRANDE DO NORTE, BRASIL
}

\author{
THE RUPESTRIC ENGRAVINGS OF THE SERIDÓ \\ ARCHAEOLOGICAL AREA, IN THE STATE OF RIO GRANDE \\ DO NORTE, BRAZIL
}

Alano Jaciguara Dantas de Alencar Martins ${ }^{1}$

Jaciguara@ymail.com

Daline Lima de Oliveira ${ }^{2}$

daline.bs@hotmail.com

Mizael Manoel Santos da Costa ${ }^{2}$

mizaelscosta16@gmail.com

Valdeci dos Santos Júnior ${ }^{3}$

\section{RESUMO}

Este artigo procura mostrar um perfil gráfico preliminar dos registros rupestres com gravuras na área arqueológica do Seridó (setor geográfico do Estado do Rio Grande do Norte), evidenciando as técnicas utilizadas, os suportes rochosos, as temáticas, a cenografia e discutir possíveis fatores ambientais nas escolhas das técnicas dos registros gráficos na paisagem natural das microrregiões (Seridó Oriental e Seridó Ocidental) da área da pesquisa.

Palavras chaves: Área arqueológica do Seridó, gravuras rupestres, paisagem.

${ }^{1}$ Programa de pós-graduação em Geografia (UERN).

${ }^{2}$ Programa de pós-graduação em Arqueologia (UFPI).

${ }^{3}$ Professor - Departamento de História - Universidade do Estado do Rio Grande do Norte (UERN). 


\begin{abstract}
This paper aims to show a preliminary graphic profile of the engraved rupestrian records in the archaeological area of Seridó (geographic sector of the state of Rio Grande do Norte), highlighting the techniques used, the rocky supports, the themes, the scenography and discussing possible environmental factors in the choices of graphic recording techniques in the natural landscape of the micro-regions (Seridó Oriental and Seridó Oeste) of the research area.
\end{abstract}

Keywords: Seridó archaeological area, rock engravings, landscape.

\title{
CONTEXTO DA PESQUISA
}

A região do Seridó Potiguar compreende uma parte do território localizada no centro-sul do estado do Rio Grande do Norte e que contempla as áreas por onde percorre o Rio Seridó e seus afluentes. Nessas áreas existem sítios arqueológicos com registros rupestres, cerâmicas e material lítico, em municípios que abrangem as microrregiões do Seridó Ocidental, Seridó Oriental, Serra de Santana e Vale do $\mathrm{Açu}^{4}$. Com a intensificação das pesquisas a partir da década de 80 do século XX, pesquisadores de arqueologia da Universidade Federal de Pernambuco começaram a intitular (apenas como uma ferramenta conceitual de georeferenciamento) o espaço dessas áreas norte-rio-grandenses e municípios paraibanos contíguos (figura 1), contendo esses sítios arqueológicos, de "Área Arqueológica do Seridó"

\footnotetext{
${ }^{4}$ A região por onde atravessa o rio Seridó e seus afluentes no Estado do Rio Grande do Norte é composta por vinte e cinco municípios: Acari, Bodó, Caicó, Carnaúba dos Dantas, Cerro Corá, Cruzeta, Currais Novos, Equador, Florânia, Ipueira, Jardim de Piranhas, Jardim do Seridó, Jucurutu, Lagoa Nova, Ouro Branco, Parelhas, Santana do Matos, Santana do Seridó, São Fernando, São João do Sabugi, São José do Seridó, São Vicente, Serra Negra do Norte, Tenente Laurentino Cruz e Timbaúba dos Batistas (NOGUEIRA, 2017).
} 
https://periodicos.ufpe.br/revistas/clioarqueologicaclioarqueologica@ufpe.br

DOI: 10.20891/clio. V35N3p170-198
Clio Arqueológica 2020, V35N3, p.170-198, MARTINS; OLIVEIRA; COSTA; SANTOS JÚNIOR

C $\underset{\text { Arqueológica }}{\operatorname{I}}$

(MARTIN, 1982, 1985, 1989, 1997, 2003; PESSIS \& MARTIN, 2002; VALLE, 2003; MUTZENBERG, 2007; BORGES, 2010; NOGUEIRA, M.; MAFRA, F. 2014; MAFRA, F. MARTIN, G. NOGUEIRA, M. 2015, 2016; NOGUEIRA, 2017).

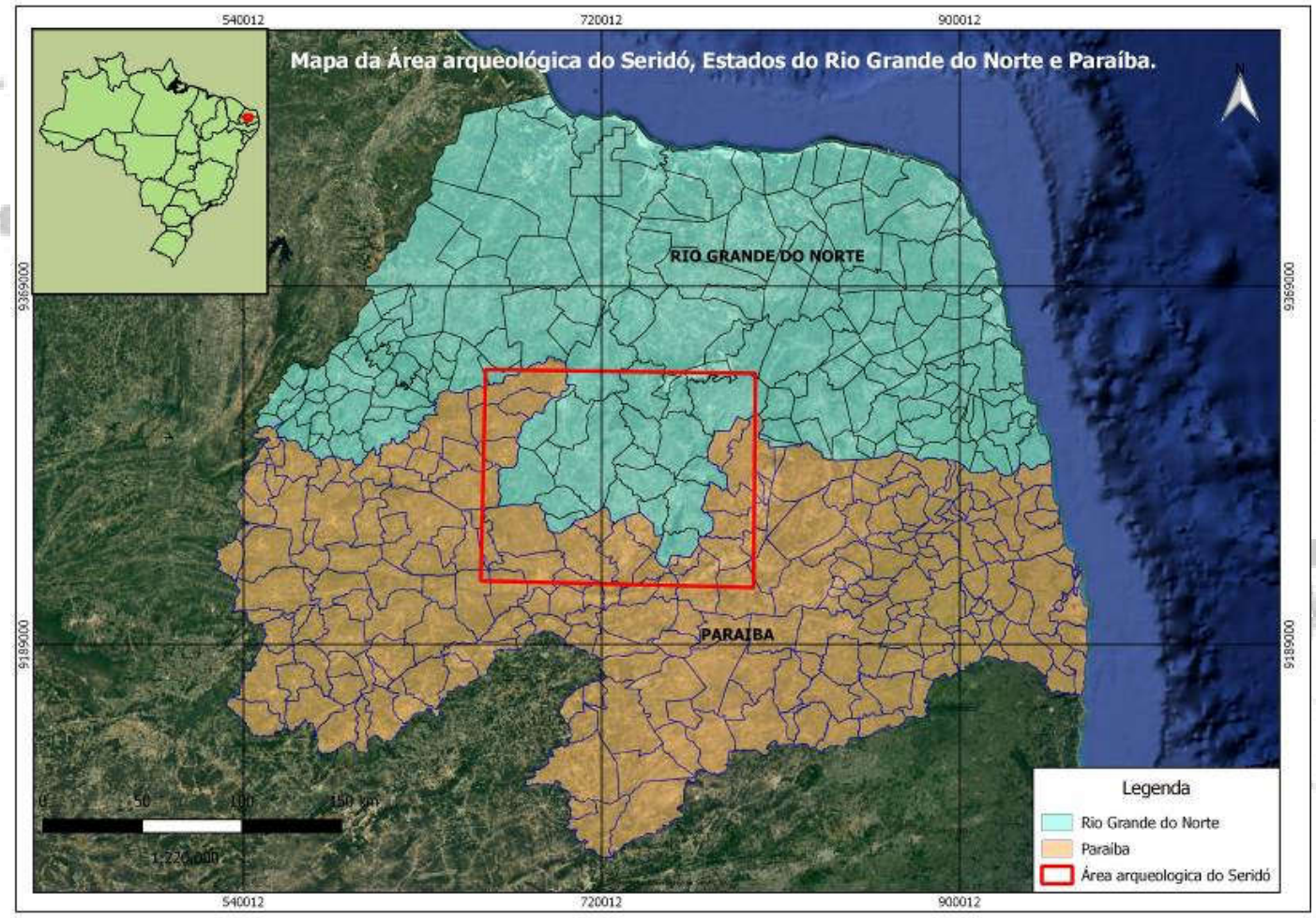

172

Figura 1: Mapa com a indicação espacial da "Área Arqueológica do Seridó” (retângulo em vermelho) abrangendo os Estados do Rio Grande do Norte e da Paraíba. Fonte: Elaboração (Alano Jaciguara, 2019) 
Nesse sentido, a "área arqueológica do Seridó" contempla mais de cinquenta (50) municípios nas proximidades dos limites fronteiriços desses Estados nordestinos, estando localizada nos extremos ocidentais do Planalto da Borborema (Figura 01), onde foi estabelecida uma cronologia de sítios arqueológicos, que remontam desde períodos iniciais do Holoceno ( \pm 10000 AP) até períodos proto-históricos e históricos, permitindo obter uma linha histórica contínua de povoamento humano na região (BORGES, 2010; NOGUEIRA, 2017).

Esse artigo irá abordar as pesquisas acadêmicas relativas aos sítios arqueológicos com registros rupestres já realizadas, mais especificamente com a técnica de elaboração de gravuras rupestres e, desenvolvidas exclusivamente, nos setores geográficos do Seridó do Estado do Rio Grande do Norte, tendo como parâmetros espaciais as subdivisões arbitrárias em microrregiões do Seridó Ocidental e do Seridó Oriental.

\section{HISTÓRICO DAS PESQUISAS COM GRAVURAS RUPESTRES NO SERIDÓ POTIGUAR}

As primeiras informações de catalogação de sítios arqueológicos com registros rupestres em solo potiguar retroagem ao final do século XVIII e início do século XIX, sendo efetuada entre 1799 e 1817 pelo padre Francisco Teles de Menezes, que registra um total de duzentos e setenta e quatro sítios com pinturas e gravuras rupestres no Nordeste brasileiro, com boa parte deles no Rio Grande do Norte e abrangendo sítios existentes na área do Seridó potiguar, que é publicada na sua obra 
"Lamentações brasílicas", onde faz as primeiras tentativas para interpretação das escritas nas pedras tentando vincular o signo rupestre com os alfabetos grego e hebraico, na busca de possíveis "tesouros escondidos" (MENESES, 1887).

Mais especificamente relacionado a menções de sítios com a técnica de elaboração com gravuras rupestres na região do Seridó, na segunda década do século XX, o pesquisador Luciano Jacques de Moraes publica a obra "Inscrições rupestres no Brasil", onde faz referência ao sítio arqueológico Pedra Lavrada, no município de São João do Sabugi, que possui a técnica de gravuras rupestres no Seridó potiguar (MORAES, 1986); entre 1924 e 1927, o agricultor seridoense José de Azevedo Dantas vasculha diversos sítios arqueológicos com registros rupestres (também com essa técnica de elaboração) no Seridó potiguar, copiando os grafismos e fazendo anotações, que iria redundar na obra "Indícios de uma civilização antiquíssima" (MARTIN, 1994).

Em 1982, pesquisadores do Departamento de Arqueologia do Museu Câmara Cascudo (vinculado a Universidade Federal do Rio Grande do Norte), publicam o trabalho "Inscrições rupestres do Rio Grande do Norte", contendo informações de sítios arqueológicos com gravuras rupestres da microrregião do Seridó oriental e da microrregião da Serra de Santana (MEDEIROS \& SOUZA, 1983).

Na década de 90 do século XX, as pesquisas se ampliam em várias vertentes e é publicado o artigo “Os sítios rupestres do Seridó, no Rio Grande do Norte (Brasil), no contexto do povoamento da América do Sul" (MARTIN, 1996); as arqueólogas 
Ana Nascimento e Suely Luna, em pesquisas a cargo do NEA-UFPE realizadas no final da década, percorrem o riacho do Bojo (onde localizam sítios com gravuras rupestres), em Carnaúba dos Dantas e publicam o artigo "Levantamento arqueológico do Riacho do Bojo, Carnaúba dos Dantas, RN, Brasil" (LUNA \& NASCIMENTO, 1998).

Em 2003 é defendida a dissertação de mestrado na UFPE intitulada "Gravuras préhistóricas da área Arqueológica do Seridó potiguar/paraibano: um estudo técnico e cenográfico" por Raoni Bernardo Maranhão Valle; em 2011 é a vez a dissertação de mestrado de Francisco de Paula Brito, também na UFPE, com o título "Análise de gravuras rupestres pré-históricas das bacias hidrográficas do Espinharas/Sabugi/Quipauá-Barra Nova no Seridó Ocidental-RN" (VALLE, 2003; BRITO, 2011) e em 2018 é defendida por Mizael Manoel Santos da Costa na UFPE, a dissertação de mestrado intitulada "Gravuras rupestres na bacia do Rio Piranhas/Açu: escolhas técnicas e morfológicas nos grafismos gravados dos sítios arqueológicos do Córrego do Peixe, Jucurutu-RN-Brasil" (COSTA, 2018).

\section{A TIPOLOGIA DOS REGISTROS RUPESTRES NO SERIDÓ POTIGUAR}

Num total de 136 sítios arqueológicos (apêndice 1) localizados até 2019 nas microrregiões do Seridó Oriental e Ocidental aparecem as duas técnicas de elaboração de registros rupestres: gravados e pintados. No geral, a quantidade de sítios arqueológicos com registros gravados é bem maior em termos percentuais que os sítios com registros pintados: são 69 sítios somente com registros gravados, 
55 sítios somente com registros pintados e 12 sítios onde aparecem as duas técnicas de execução.

Levando em conta somente os termos estatísticos, a princípio poderia se levantar a hipótese de que os grupos pretéritos (autores dos registros rupestres) que ocuparam essas duas microrregiões dominavam em sua grande maioria a técnica das gravuras, entretanto é necessário alertar que existem variações entre as duas microrregiões: na microrregião do Seridó Ocidental a predominância quase absoluta é de registros gravados, enquanto na microrregião do Seridó Oriental a predominância já passa a ser dos registros pintados.

No sentido espacial essa diferenciação técnica está bem delimitada: no espaço geográfico onde está situada a maior parte dos municípios da microrregião do Seridó Ocidental, tais como Serra Negra do Norte, São João do Sabugi, Ipueira, Timbaúba dos Batistas, São Fernando, Jardim de Piranhas, Ouro Branco e Caicó, a predominância quase absoluta são de sítios arqueológicos com gravuras; por outro lado, no espaço geográfico da microrregião do Seridó Oriental que abrange os municípios de Parelhas, Acari, Carnaúba dos Dantas, Currais Novos, Santana do Seridó, Jardim do Seridó, São José do Seridó e Cruzeta, a predominância são de sítios arqueológicos com pinturas. 


\section{OS SUPORTES LITOLÓGICOS UTILIZADOS NA ELABORAÇÃO DAS}

\section{GRAVURAS}

A região do Seridó Ocidental está situada na chamada depressão interplanáltica central em torno do Planalto da Borborema e do Planalto Sertanejo, com feições geomorfológicas diferenciadas onde aparecem cristas quartzíticas e topos convexos esculpidos em granitos e gnaisses (BRITO 2011); por exemplo, uma boa parte dos sítios arqueológicos dos municípios de Serra Negra do Norte e Timbaúba dos Batistas estão compostos por ortognaisses (figuras 2 e 3), enquanto em outros espaços (município de Caicó, por exemplo), aparecem suportes em granitóides e marmorizados (figuras 4 e 5).
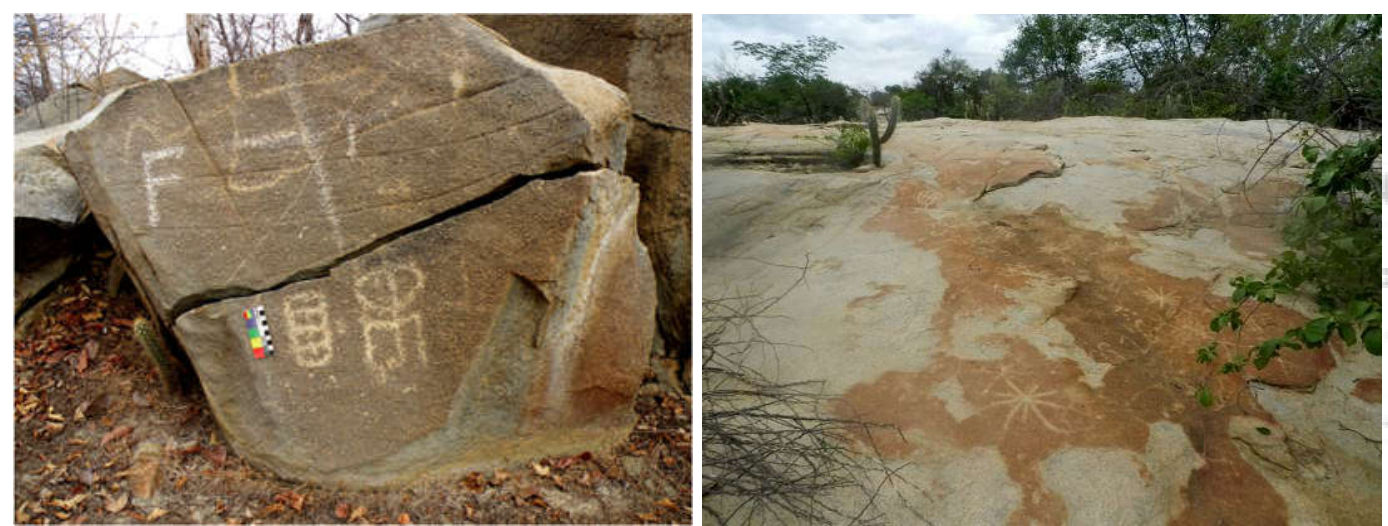

Figuras 2 e 3 - Técnicas de gravuras em formação rochosa (ortognaisses) vertical (Sítio arqueológico Pintado - Timbaúba dos Batistas - RN \{Seridó Ocidental\}) e formação rochosa sub-horizontal (Sítio arqueológico Riacho das Emas - Serra Negra do Norte - RN \{Seridó Ocidental\}). 

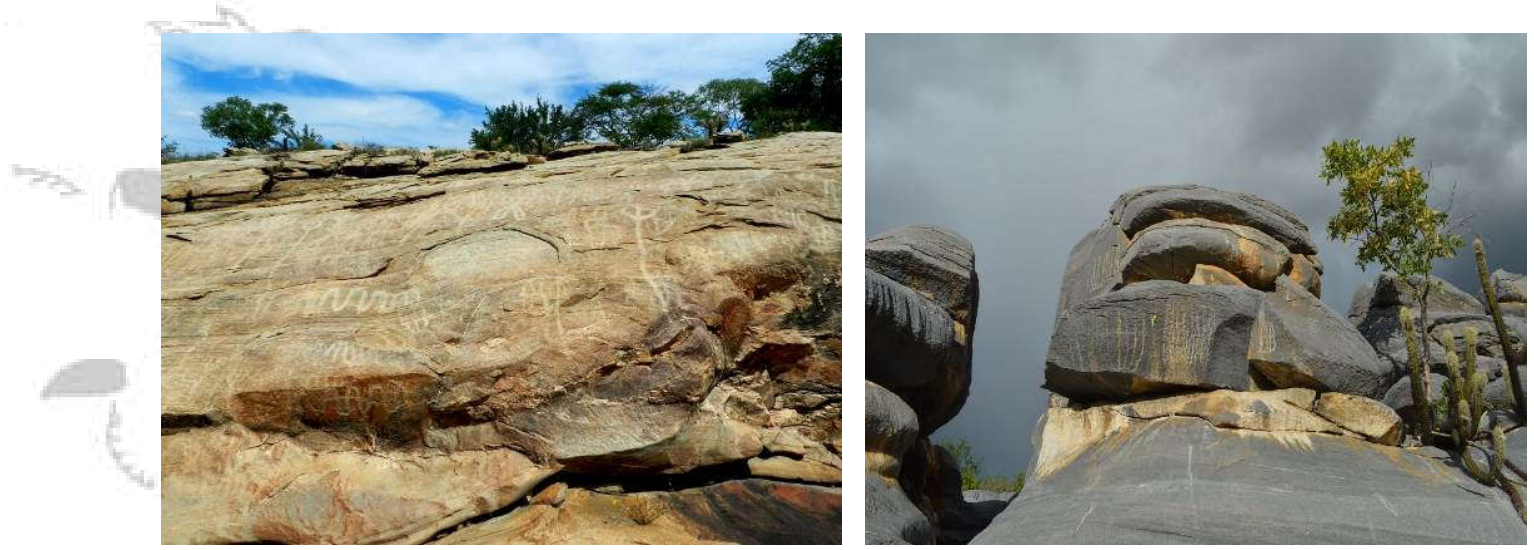

Figuras 4 e 5 - Exemplos de técnica de gravuras em formação rochosa sub-horizontal de granitóides (Sítio arqueológico Cachoeira da Serra \{Samanaú\} - Caicó - RN \{Seridó Ocidental\}) e suporte rochoso marmorizado (Sítio arqueológico Pedra Preta - Caicó - RN $\{$ Seridó Ocidental\}).
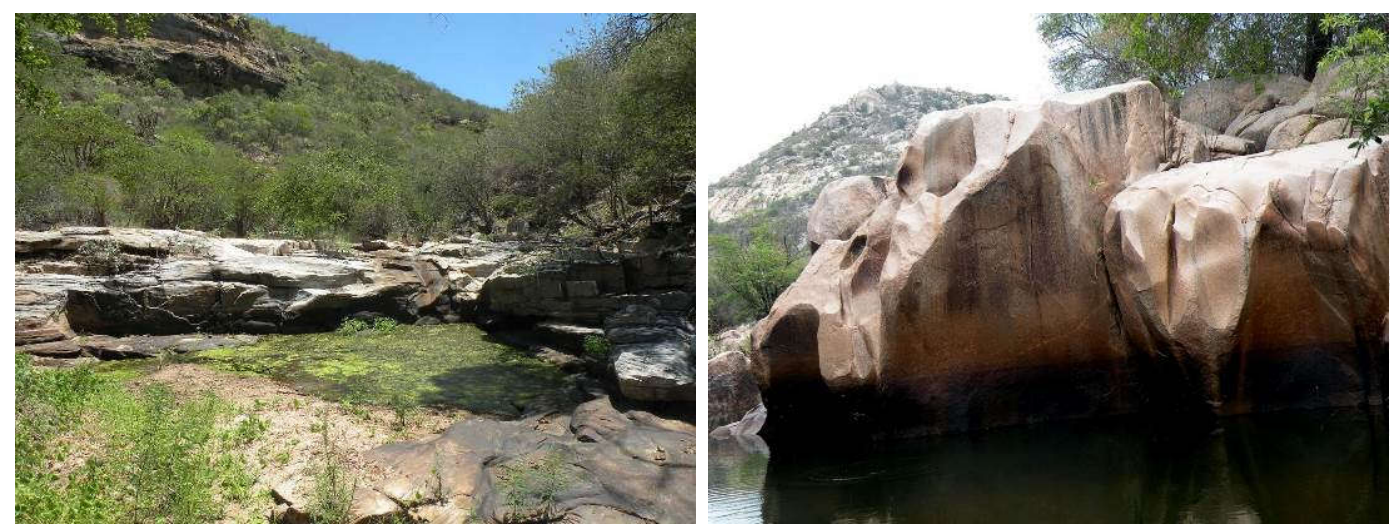

Figuras 6 e 7 - Formações rochosas próximas a depósitos de água (Sítio arqueológico Lagoa do Caramungu - Carnaúba dos Dantas-RN \{Seridó Oriental\}) e formações rochosas graníticas verticais no leito ou nas margens de riachos (Sítio arqueológico Poço do Arthur II - Acari - RN \{Seridó Oriental\}). 
No Seridó Oriental a opção predominante dos suportes rochosos foi por formações rochosas isoladas (geralmente semi-ovaladas) ou próximas a depósitos naturais de água (figuras 6 e 7), tais como lagoas e depressões naturais, leitos e margens de riachos, onde essa proximidade da água é indissociável dos registros gravados.

\section{GRAVURAS RUPESTRES DO SERIDÓ OCIDENTAL}

No Seridó Ocidental composto pelos municípios de Serra Negra do Norte, Jardim de Piranhas, São João do Sabugi, Ipueira, Timbaúba dos Batistas, São Fernando, Ouro Branco e Caicó, é predominante a técnica de gravuras rupestres. Esses registros geralmente estão localizados nas rochas próximas aos olhos d'águas, em lajedos graníticos rentes ao solo/sub-horizontais localizados nas margens de riachos ou em suas formações rochosas laterais.

Nos suportes compostos por formações rochosas laterais, as representações gráficas variam em termos de altura em relação ao solo, por vezes ocupando todo o espaço do suporte. Ainda não foram localizados indícios de preparação antecipada do suporte (alisamentos/polimentos). Já nos suportes rochosos rentes ao solo (afloramentos do embasamento), a presença dos registros gravados, pelo menos visualmente, indica a possibilidade de que sofram um processo mais acentuado de intemperização (esfoliação esferoidal - também conhecida popularmente como "efeito cebola") que vai lentamente originando etapas de desplacamento da crosta rochosas onde foram elaboradas as criações simbólicas. 

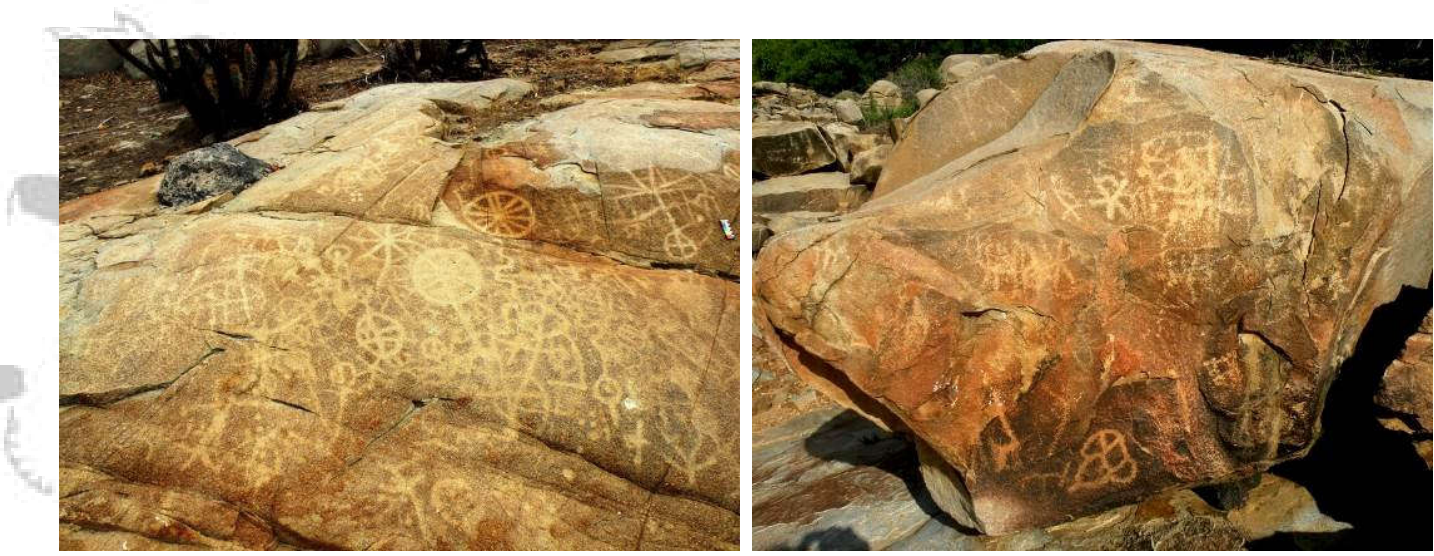

Figuras 8 e 9 - Ocorrências frequentes de sobreposições gráficas (Sítio arqueológico

Pintado - Timbaúba dos Batistas - RN) e predominância de grafismos abstratos (Sítio arqueológico Pedra Lavrada - São João do Sabugi - RN).

É bastante comum encontrar sítios arqueológicos com grafismos espaçados e/ou incompletos devido a esse processo intempérico. As principais técnicas utilizadas são a raspagem ${ }^{5}$ e o picoteamento ${ }^{6}$ (sendo mais usual a utilização conjunta das duas técnicas) com ocorrência frequente de sobreposições (vide exemplo na figura 8) entre os grafismos com dimensões variáveis. As temáticas mais utilizadas são de grafismos abstratos (vide exemplo na figura 9) com raros motivos figurativos

\footnotetext{
${ }^{5}$ A raspagem é proveniente de um gesto que aplica contato superficial entre dois corpos (percutor e um suporte), em sentido unidirecional ou bidirecional, isto é, a mão que empunha o instrumento abrasivo executa movimentos num único sentido ou em dois (ida e volta), que deixa visíveis irregularidades nas bordas e no interior dos sulcos, oriundas da textura natural da rocha ou de percussão, quando precedida por esta, ou seja, é realizado através de contato direto de duas superfícies abrasivas (PESSIS, 2002; VALLE, 2003; SANTOS JÚNIOR, 2014);

${ }^{6}$ A técnica da picotagem abrange posturas corporais na quando da elaboração das gravuras onde os sulcos dos grafismos são obtidos por intermédio de uma série de pequenos impactos contínuos feitos com um instrumento (percutor). (PESSIS, 2002; VALLE, 2003; SANTOS JÚNIOR, 2014).
} 
(quase sempre representações de zoomorfos e ocorrências esporádicas de antropomorfos esquemáticos). Os traços curvilíneos são bastante utilizados na elaboração de esferas e círculos concêntricos com ou sem intercalações.

\section{GRAVURAS RUPESTRES DO SERIDÓ ORIENTAL}

Na microrregião do Seridó Oriental (composto pelos municípios de Parelhas, Acari, Carnaúba dos Dantas, Currais Novos, Santana do Seridó, Jardim do Seridó, São José do Seridó e Cruzeta), as gravuras rupestres também mantêm as mesmas características do Seridó Ocidental, pelo menos em termos de preferências por elaboração de grafismos em suportes rochosos verticais (figuras 10 e 11) ou subhorizontais, mas já aparecem também algumas opções por grutas e semiabrigos.
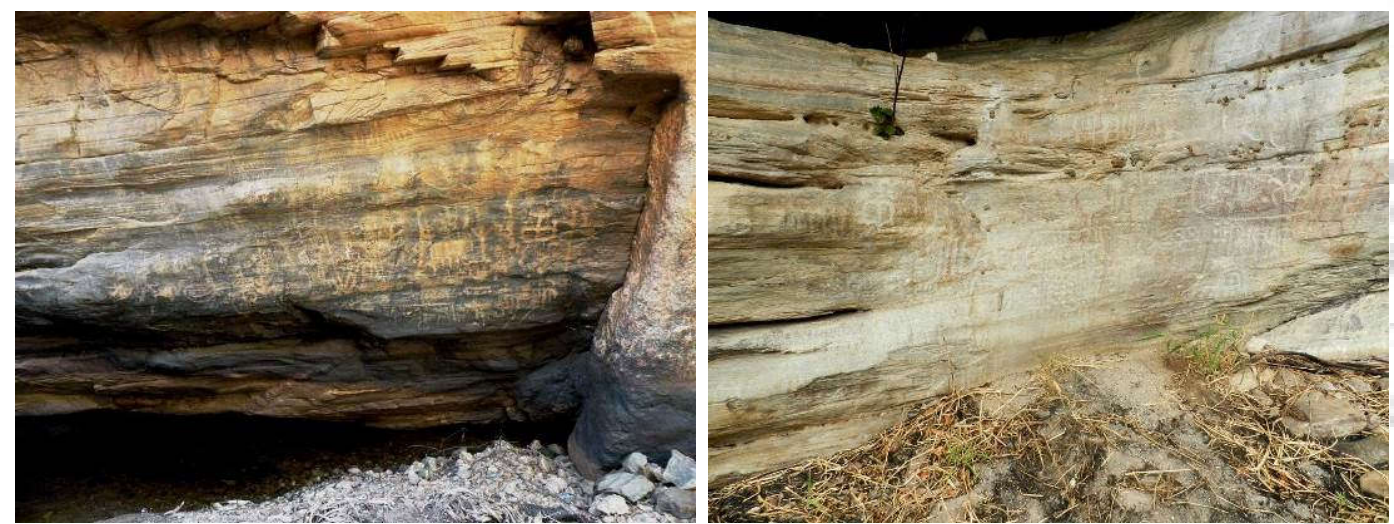

Figuras 10 e 11 - Elaboração de gravuras em suportes rochosos verticais (Sítio Arqueológico Grota Funda - Carnaúba dos Dantas - RN) e (Sítio arqueológico do Letreiro - Equador - RN). 
A técnica de execução mais frequente é a da raspagem simples associada com a técnica do picoteamento; em alguns sítios arqueológicos, uma boa parte das gravuras (por estarem situadas no leito ou em afloramentos das margens) sofreu a ação posterior da água dos riachos ou de enchentes, provocando um polimento natural nas concavidades dos registros (figuras 12 a 13). Quanto aos temas representados, a predominância quase absoluta é de grafismos abstratos (vide exemplo na figura 14), onde os registros reconhecíveis são mais raros e compostos essencialmente por antropomorfos e zoomorfos esquemáticos (figura 15).
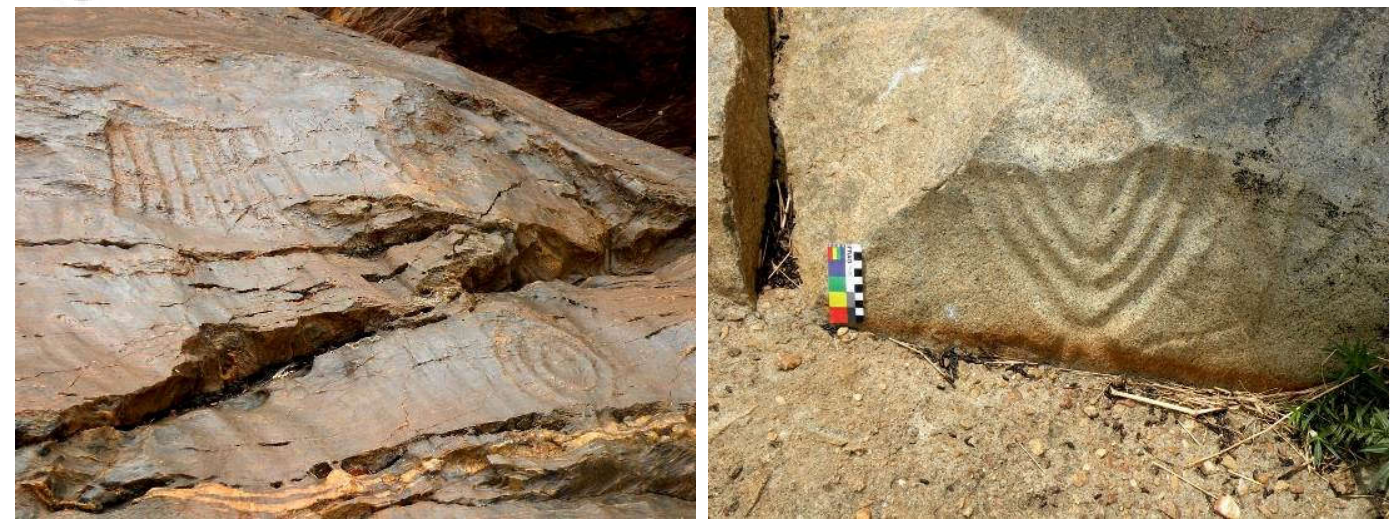

Figuras 12 e 13 - Gravuras com polimento posterior devido a ação das águas (Sítio Arqueológico Tanque dos Marimbondos - Carnaúba dos Dantas - RN) e (Sítio arqueológico Tanques - Jardim do Seridó - RN).

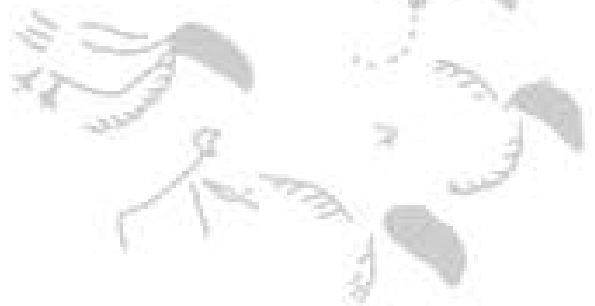



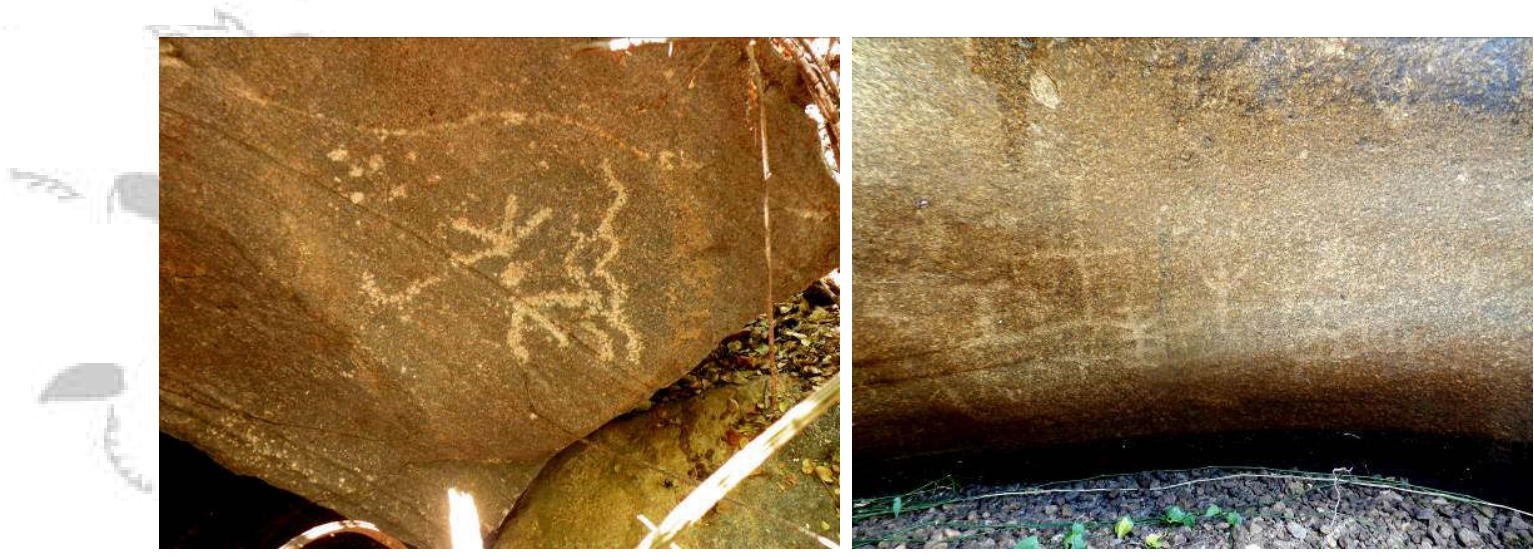

Figuras 14 e 15 - Grafismos abstratos (Sítio Arqueológico Fazenda Olho d'água - Cruzeta

- RN) e representações esquemáticas de zoomorfos/antropomorfos (Sítio arqueológico Tanques da Barra da Carnaúba - Acari - RN).

CONSIDERAÇÕES GEOAMBIENTAIS E A DISTRIBUIÇÃO DOS SÍTIOS

\section{NA PAISAGEM}

$\mathrm{Na}$ análise geoambiental, a questão da água é fundamental para se entender a distribuição espacial dos sítios arqueológicos com gravuras rupestres nas microrregiões do Seridó Oriental e Ocidental.

Com concentrações geológicas de formações rochosas constituídas essencialmente por gnaisses, ortognaisses, quartzitos, granitoides e afloramentos marmorizados, aliada a uma vegetação predominantemente composta pela Caatinga hiperxerófila, a chegada do período invernoso é vital para a manutenção da vida nessas áreas. Numa área sujeita a secas periódicas, as disputas pelos espaços, na obtenção da 
comida deveria ser acirrada, transformando-se naturalmente em conflitos entre os grupos pré-coloniais.

Como os caminhos naturais utilizados nas migrações dos grupos pretéritos eram os rios e os riachos, principalmente os grupos nômades que viviam da caça e da coleta de alimentos, não causa nenhuma surpresa a existência de uma quantidade considerável de registros rupestres gravados nessas duas microrregiões do Seridó. Vários desses grupos, na maior parte em períodos cronológicos ainda indeterminados (as datações com restos ósseos das pesquisas arqueológicas efetuadas pela UFPE chegam a retroagir a 9.400 antes do presente), ocuparam o espaço existente entre as serras elevadas (Planalto da Borborema) que delimitam a divisa entre a Paraíba e o Rio Grande do Norte (caso do município de Equador-RN) e a Serra de Santana.

Dessa forma, o espaço geográfico da região é caracterizado pelo bioma da caatinga, de clima semiárido, que apresenta secas prolongadas, relevo com formações antigas, solos sujeitos a erosão intensa e um sistema hidrológico com baixo potencial. A topografia apresenta dois tipos básicos de configuração: área ocupada pelo Planalto da Borborema e outra área ocupada pela Depressão Sertaneja. O Planalto da Borborema são segmentos dos dobramentos das rochas Pré-cambrianas que se elevam a altitudes que variam entre 50 a 800 metros, com litologias do cristalino. São maciços antigos retrabalhados por processos erosivos durante o Terciário. 
O outro espaço geográfico é composto pela depressão sertaneja que apresenta um relevo levemente ondulado composto por serrotes entrecortados e planícies e é ocupado atualmente, no sentido político, por vários municípios no Estado potiguar que possuem uma quantidade considerável de sítios arqueológicos com gravuras rupestres; essa Depressão Sertaneja existente no Seridó contorna o Planalto da Borborema nas suas partes mais baixas, formando vales.

Os tipos de solos mais comuns na região são o Luvissolos Crômicos e o Neossolo Litólico, onde o luvissolo crômico no Seridó apresenta ondulações formando vales, sendo comum a presença de inselbergs. O solo é raso, de coloração avermelhada viva devido à argila (oxidação do ferro), apresentando fases pedregosas, suscetível à erosão e com bom nível de drenagem, o que significa dizer que a água que o solo absorve é facilmente removida pela evaporação. O Neossolo Litólico trata-se de um solo pouco desenvolvido, raso ou muito raso (cerca de $40 \mathrm{~cm}$ de profundidade) e assentado diretamente sobre rochas ou materiais da rocha do embasamento cristalino.

Quanto à distribuição espacial dos sítios arqueológicos, como já mencionado, existe uma divisão bem nítida quanto à técnica de execução da simbologia rupestre nas duas microrregiões do Seridó potiguar: na microrregião do Seridó Ocidental foi identificada uma predominância quase absoluta da técnica dos registros gravados (de 37 sítios com registros rupestres, 36 deles possui somente a técnica de gravuras); já na microrregião do Seridó Oriental essa tendência se inverte e a técnica de 
pinturas é quem predomina (de 99 sítios com registros rupestres, 55 deles possui somente a técnica de pinturas, 11 deles possui as técnicas de pinturas e gravuras associadas e 33 deles possui somente a técnica de gravuras) (vide figura 16).

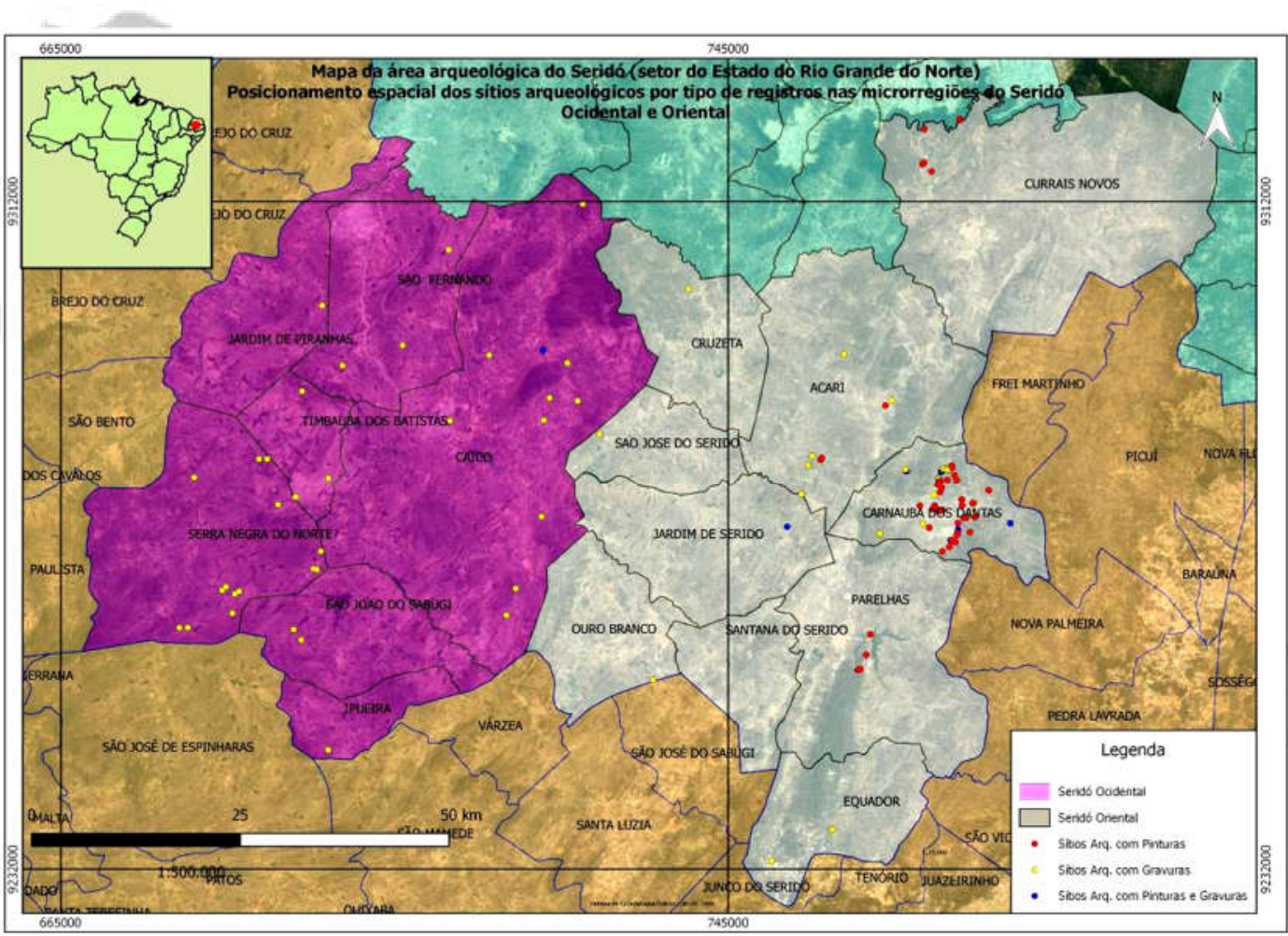

Figura 16 - Mapa evidenciando a divisão de escolhas de técnicas de elaboração dos registros rupestres na área Arqueológica do Seridó (setor geográfico do Rio Grande do Norte): a Microrregião Ocidental com predominância da técnica de gravuras e a Microrregião Oriental com a predominância da técnica de Pinturas. Fonte: Elaboração (Alano Jaciguara, 2019). 
Especificamente com relação às pinturas realizadas nos sítios arqueológicos da microrregião do Seridó Oriental, foi possível observar que os abrigos rochosos em quartzito e biotita-xisto, geralmente localizados em média vertente e próximo aos cursos de água, foram os locais preferenciais para a prática gráfica. Os posicionamentos geomorfológicos e aspectos litológicos desses lugares talvez expliquem essa opção:

Esta disposição pode ser explicada pelo melhor resultado para a prática gráfica encontrada no suporte rochoso em quartzito que em biotita-xisto. Enquanto a primeira litologia é mais clara e mais resistente, a segunda é mais escura e mais friável, levando à difícil visualização das pinturas além de ocasionar uma menor preservação. Os abrigos também têm formas diferentes, mesmo tratando-se de encostas negativas, pois o quartzito, por ser mais resistente ao intemperismo que o biotita-xisto, geralmente apresenta uma forma côncava com proteção rochosa lateral (MUTZEMBERG, 2007: 124).

Já os sítios com a técnica de gravuras ocupam matacões e afloramentos no leito ou margens de cursos de água em fundo de vale, com suportes de rochas quartzíticas ou ortognaisses; essa opção por gravar os registros em afloramentos sub-horizontais e matacões verticais em fundo de vale, no leito de drenagens, na maioria dos casos com a presença de marmitas, tanques ou estreitamentos rochosos que armazenam água (somente no riacho do Bojo, em Carnaúba dos Dantas, foram identificados 23 sítios com gravuras e que possuem essas características), pode estar relacionada ao 
alto dispêndio de energia necessária para técnica de gravação com consequente maior consumo deste líquido, o que talvez tenha limitado este tipo de técnica a ambientes com maior disponibilidade deste recurso (PESSIS, 2002; SANTOS JÚNIOR, 2008, 2014).

Por outro lado, quanto a morfologia do suporte rochoso na microrregião do Seridó Ocidental, do total de 37 sítios, apenas dois sítios tiveram gravuras elaboradas em semiabrigos (Ilha de Santana e Gruta da Caridade, no município de Caicó - RN), sendo todos os demais com elaborações de gravuras em afloramentos subhorizontais, localizados a céu aberto e nas proximidades de cursos de água.

São várias as possíveis causas dessa distinção espacial com relação às técnicas de execução dos registros nessas duas microrregiões, entre elas, podem ser citadas opções preferenciais por determinados tipos de suportes rochosos, ocupações de áreas geoambientais por grupos específicos, fatores paleoambientais ligados a potenciais hidrográficos, geológicos ou alterações climáticas, migrações forçadas ou até mesmo, ausência de matérias primas para elaboração de tintas em alguns contextos ambientais.

As escolhas desses locais na paisagem natural dessas áreas por assentamentos humanos pretéritos permitem pressupor que, critérios geomorfológicos, tais como, como altimetria, declividade e posicionamento espacial dos abrigos rochosos e dos afloramentos rochosos em relação aos cursos de água existentes, provavelmente 
influenciaram nas escolhas das técnicas de execução dos registros rupestres a serem elaboradas (MARTINS, 2018).

\section{CONCLUSÕES}

A expressiva quantidade de sítios arqueológicos com gravuras rupestres com temáticas e técnicas diferenciadas na área arqueológica do Seridó (no setor geográfico analisado do Estado do Rio Grande do Norte) evidencia a possibilidade de ocupações contínuas desses espaços pelos grupos humanos pré-coloniais e coloniais em períodos cronológicos também diferenciados. Essas ocupações provavelmente se estenderam até o final do século XVII quando ocorrem intensos combates na região, no episódio conhecido como "a guerra dos bárbaros", envolvendo os grupos indígenas e os colonizadores.

Dos 136 sítios arqueológicos com registros gráficos identificados nas duas microrregiões (Seridó Oriental e Seridó Ocidental), 69 deles possuem exclusivamente a técnica da elaboração de gravuras rupestres $(50 \%$ do total de sítios) e essa técnica aparece também em mais 12 sítios associada com a técnica de pinturas; já a técnica de pinturas aparece de forma exclusiva em 55 sítios (40\% do total de sítios).

Embora exista uma pequena vantagem numérica da técnica de gravuras no montante geral dos sítios arqueológicos da área arqueológica do Seridó, torna-se necessário analisar a distribuição espacial desses sítios nas duas microrregiões 
(Seridó Oriental e Ocidental) para perceber uma preferência da técnica de pinturas na microrregião do Seridó Oriental e uma preferência quase absoluta pela técnica de gravuras na microrregião do Seridó Ociental. O aprofundamento das pesquisas arqueológicas acadêmicas envolvendo questões paleoclimáticas, hidrográficas e fatores litológicos talvez venha a explicar futuramente, de forma mais detalhada, essa diferenciação observada atualmente.

Essas diferenciações se estendem também as temáticas representadas nas duas técnicas de elaborações: as pinturas apresentam um percentual bem maior de elaboração de motivos figurativos (antropomorfos, zoomorfos, fitomorfos e artefatos) em relação às gravuras.

De forma mais sintética, foi possível elaborar, por enquanto, um perfil gráfico preliminar com algumas características observadas a partir do conjunto de sítios com a técnica de gravuras nas duas microrregiões (quadro 1) da área Arqueológica do Seridó (no setor geográfico do Estado do Rio Grande do Norte): 


\begin{tabular}{|c|c|c|c|c|}
\hline Tipologia & $\begin{array}{l}\text { Suporte rochoso } \\
\text { Matérias primas }\end{array}$ & $\begin{array}{l}\text { Técnicas de } \\
\text { elaboração }\end{array}$ & Temáticas & Cenografias \\
\hline & Gnaisses & raspagens & $\begin{array}{l}\text { Grafismos } \\
\text { abstratos } \\
\text { (predominância) }\end{array}$ & \multirow[t]{2}{*}{$\begin{array}{l}\text { Sobreposições gráficas } \\
\text { (constantes) }\end{array}$} \\
\hline \multirow[t]{4}{*}{ Gravuras } & Ortognaisses & picotagem & $\begin{array}{l}\text { Raros motivos } \\
\text { figurativos }\end{array}$ & \\
\hline & Quartzitos & Microrregião & \multicolumn{2}{|c|}{ Posicionamento geomorfológico dos suportes } \\
\hline & Granitóides & Oriental & \multicolumn{2}{|c|}{$\begin{array}{l}\text { Afloramentos sub-horizontais e matacões } \\
\text { verticais nas margens e leito de drenagens em } \\
\text { cotas altimétricas mais elevadas } \\
\text { (predominância) }\end{array}$} \\
\hline & $\begin{array}{l}\text { Afloramentos } \\
\text { marmorizados }\end{array}$ & Ocidental & \multicolumn{2}{|c|}{$\begin{array}{l}\text { Afloramentos sub-horizontais nas margens e } \\
\text { leito de drenagens em cotas altimétricas mais } \\
\text { baixas (predominância) }\end{array}$} \\
\hline
\end{tabular}

Quadro 1: Perfil gráfico preliminar das gravuras rupestres das microrregiões do Seridó Oriental e Ocidental da área Arqueológica do Seridó (RN) (setor geográfico do Estado do Rio Grande do Norte), Fonte: Elaborado pelos autores, 2019.

\section{REFERÊNCIAS BIBLIOGRÁFICAS}

BORGES, Fabio Mafra. 2010. Os sítios arqueológicos Furna do Umbuzeiro e Baixa do Umbuzeiro: caracterização de um padrão de assentamento na área arqueológica do Seridó - Carnaúba dos Dantas - RN, Brasil. Tese de Doutorado, Programa de Pós-Graduação em Arqueologia, Universidade Federal de Pernambuco.

BRITO, F. P. 2011. Análise de gravuras rupestres pré-históricas das bacias hidrográficas do Espinharas/Sabugi/Quipauá-Barra Nova no Seridó ocidental-RN. Dissertação de Mestrado, Universidade Federal de Pernambuco.

COSTA, Mizael Manoel Santos da. 2018, Gravuras Rupestres na Bacia do Rio Piranhas/Açu: escolhas técnicas e morfológicas nos grafismos gravados dos sítios 
arqueológicos do Córrego do Peixe, Jucurutu-RN-Brasil. Dissertação de Mestrado, Universidade Federal de Pernambuco.

LUNA, Suely; NASCIMENTO, Ana. 1998. "Levantamento arqueológico do Riacho do Bojo, Carnaúba dos Dantas, RN, Brasil”. Clio: Série arqueológica, Recife. v. 1 (13), 173 186.

MAFRA, F. MARTIN, G. NOGUEIRA, M. 2014. "Intervenções arqueológicas em sítios a céu aberto na área arqueológica do Seridó: os sítios Meggers I e Meggers III - Parelhas RN, Brasil”. Clio arqueológica, Recife, v. 30 (1), 10-37.

MAFRA, F. MARTIN, G. NOGUEIRA, M. 2015. "Sítios a céu aberto na região do Seridó Potiguar: um estudo de caso do rio da Cobra, entre os municípios de Carnaúba dos Dantas e Parelhas, RN". Clio arqueológica, Recife, v. 31 (3), 113-132.

MARTIN, Gabriela. 2003. "Fronteiras estilísticas e culturais na arte rupestre da área Arqueológica do Seridó (RN, PB)"'. Clio: Série arqueológica. Recife, v. 1 (16), 11-32. 1985. "Arte rupestre no Seridó (RN): O Sítio Mirador do Boqueirão de Parelhas". Clio: Revista do curso de mestrado em História. Recife, n. 07.

. 1982. "Casa Santa: um abrigo com pinturas rupestres no Estilo Seridó, no Rio Grande do Norte". Clio, v. 5 Recife.

1989. “A subtradição Seridó de pintura rupestre do Brasil”. Clio arqueológica, Recife, v.1 (5), 19-26.

. "Os sítios rupestres do Seridó, no Rio Grande do Norte (Brasil) no contexto do povoamento da América do Sul". 1996. FUNDHAMentos. São Raimundo Nonato, PI, v. 1 (1), 339.346.

1997. Pré-História do Nordeste do Brasil. Recife: Universitária da UFPE.

MARTIN, Gabriela. 1994. Apresentação. In: DANTAS, José de Azevêdo. Indícios de uma civilização antiquíssima. João Pessoa: Governo do Estado/Secretaria de Educação e Cultura/Fundação Casa de José Américo/IHGPB/A União (Biblioteca Paraibana, XI). 
MARTINS, Alano Jaciguara Dantas de Alencar. 2018. Estudo das características geoambientais dos padrões de assentamentos com registros rupestres no Sertão Potiguar. Dissertação de mestrado, Programa de Pós-Graduação em Geografia, Universidade do Estado do Rio Grande do Norte, Mossoró.

MEDEIROS, Osmar. SOUZA, Maurina Sampaio. 1983. "Inscrições rupestres do Rio Grande do Norte". Coleção de textos acadêmicos, n'. 204, Museu Câmara Cascudo, UFRN, Natal-RN.

MENESES, Francisco Corrêa Telles. 1887. Lamentação brasílica. (manuscrito original existente no Instituto Histórico e Geográfico Brasileiro localizado no Rio de Janeiro. Obra comentada por Tristão de Alencar Araripe na Revista do Instituto Histórico e Geográfico). v.50, 74, Rio de Janeiro.

MORAES, Luciano Jacques de. 1986. "Inscrições rupestres no Brasil" Edição fac-similar da 1'Ed" IFOCS/UMMP. Coleção Mossoroense, v. cccXXVI', série ID, n" 64. ESAMÆGD: Mossoró.

MUTZENBERG, D. S. 2007. Gênese e ocupação pré-histórica do Sítio Arqueológico Pedra do Alexandre: uma abordagem a partir da caracterização paleoambiental do Vale do Rio Carnaúba-RN. Dissertação de Mestrado, Universidade Federal de Pernambuco. Recife.

NOGUEIRA, M. 2017. Ocupações pré-históricas a céu aberto no vale do Rio da Cobra Carnaúba dos Dantas e Parelhas - RN. Tese de Doutorado, Programa de Pós-Graduação em Arqueologia, Universidade Federal de Pernambuco, Recife.

NOGUEIRA, M.; MAFRA, F. 2014. "Levantamento de sítios arqueológicos a céu aberto na Área 1 Arqueológica do Seridó - Rio Grande do Norte - Brasil”. MNEME - revista de humanidades, Caicó, v. 15 (35), 244-259.

PESSIS, A. M. 2002. "Do estudo das gravuras rupestres pré-históricas no Nordeste do Brasil". Clio série arqueológica, $\mathrm{n}^{\circ}$. 15, 29-44.

PESSIS, Anne-Marie. MARTIN, Gabriela. 2002. “Área arqueológica de Seridó, RN, PB: Problemas de Conservação do Patrimônio Cultural”. FUMDHAMentos II, v.1 (2), São Raimundo Nonato, Piauí. 
SANTOS JÚNIOR, V. 2014. “As Gravuras Rupestres da Região Oeste do Rio Grande do Norte". Revista Contexto, v. 4 (1-2), 81-92. . 2008. "As técnicas de execução das gravuras rupestres do Rio Grande do Norte". FUMDHAMentos, v. VII, 516-528.

VALLE, R. 2003. Gravuras Pré-históricas da Área Arqueológica do Seridó Potiguar/Paraibano: Um Estudo Técnico e Cenográfico. Dissertação de mestrado, Universidade Federal de Pernambuco, Recife. 


\section{APÊNDICE 1}

(Relação dos 136 sítios arqueológicos com registros rupestres na Área Arqueológica do Seridó Setor do Estado do Rio Grande do Norte)

\begin{tabular}{|c|c|c|c|c|}
\hline $\mathbf{N}^{\mathbf{0}}$ & Microrregião & Município & Sítio Arqueológico & Tipo de registro \\
\hline 01 & Seridó Oriental & Acari & Açude Grossos & Gravuras \\
\hline 02 & Seridó Oriental & Acari & Caiçarinha I & Pinturas \\
\hline 03 & Seridó Oriental & Acari & Caiçarinha II & Pinturas \\
\hline 04 & Seridó Oriental & Acari & Fazenda Pinturas & Gravuras \\
\hline 05 & Seridó Oriental & Acari & Furna da Onça & Pinturas \\
\hline 06 & Seridó Oriental & Acari & Poço do Artur I - Arroz & Gravuras \\
\hline 07 & Seridó Oriental & Acari & Poço do Artur II - Canoas & Gravuras \\
\hline 08 & Seridó Oriental & Acari & Tanques da Barra da Carnaúba & Gravuras \\
\hline 09 & Seridó Ocidental & Caicó & Cachoeira da Serra de São Bernardo & Gravuras \\
\hline 10 & Seridó Ocidental & Caicó & Cachoeira do Sítio Alegre & Pinturas/gravuras \\
\hline 11 & Seridó Ocidental & Caicó & Curumins & Gravuras \\
\hline 12 & Seridó Ocidental & Caicó & Gruta da Caridade & Gravuras \\
\hline 13 & Seridó Ocidental & Caicó & Ilha de Santana & Gravuras \\
\hline 14 & Seridó Ocidental & Caicó & Mundo Novo & Gravuras \\
\hline 15 & Seridó Ocidental & Caicó & Palma & Gravuras \\
\hline 16 & Seridó Ocidental & Caicó & Pedra Preta & Gravuras \\
\hline 17 & Seridó Ocidental & Caicó & Poço de São Bernardo & Gravuras \\
\hline 18 & Seridó Ocidental & Caicó & Saco do Bode & Gravuras \\
\hline 19 & Seridó Ocidental & Caicó & Serrote Grande do Riacho dos Cavalos & Gravuras \\
\hline 20 & Seridó Ocidental & Caicó & Várzea Comprida & Gravuras \\
\hline 21 & Seridó Oriental & Carnaúba dos Dantas & Bojo I & Pinturas/gravuras \\
\hline 22 & Seridó Oriental & Carnaúba dos Dantas & Bojo II & Gravuras \\
\hline 23 & Seridó Oriental & Carnaúba dos Dantas & Bojo III & Gravuras \\
\hline 24 & Seridó Oriental & Carnaúba dos Dantas & Bojo IV & Gravuras \\
\hline 25 & Seridó Oriental & Carnaúba dos Dantas & Cachoeira das Canoas I & Gravuras \\
\hline 26 & Seridó Oriental & Carnaúba dos Dantas & Cachoeira das Canoas II & Gravuras \\
\hline 27 & Seridó Oriental & Carnaúba dos Dantas & Casa de Pedra & Pinturas/gravuras \\
\hline 28 & Seridó Oriental & Carnaúba dos Dantas & Cachoeira do Bojo & Gravuras \\
\hline 29 & Seridó Oriental & Carnaúba dos Dantas & Cachoeira do Chapéu & Pinturas/gravuras \\
\hline 30 & Seridó Oriental & Carnaúba dos Dantas & Cachoeira do Letreiro & Pinturas/gravuras \\
\hline 31 & Seridó Oriental & Carnaúba dos Dantas & Cachoeira do Maracajá & Gravuras \\
\hline 32 & Seridó Oriental & Carnaúba dos Dantas & Cacimba dos Três Perdidos & Gravuras \\
\hline 33 & Seridó Oriental & Carnaúba dos Dantas & Casa Santa & Pinturas \\
\hline 34 & Seridó Oriental & Carnaúba dos Dantas & Fundões I & Gravuras \\
\hline 35 & Seridó Oriental & Carnaúba dos Dantas & Fundões II & Gravuras \\
\hline
\end{tabular}




\begin{tabular}{|c|c|c|c|c|}
\hline $\mathbf{N}^{\circ}$ & Microrregião & Município & Sítio Arqueológico & Tipo de registro \\
\hline 36 & Seridó Oriental & Carnaúba dos Dantas & Fundões III & Pinturas/gravuras \\
\hline 37 & Seridó Oriental & Carnaúba dos Dantas & Furna da Desilusão & Pinturas \\
\hline 38 & Seridó Oriental & Carnaúba dos Dantas & Furna da Ema & Pinturas \\
\hline 39 & Seridó Oriental & Carnaúba dos Dantas & Furna da Jararaca & Pinturas \\
\hline 40 & Seridó Oriental & Carnaúba dos Dantas & Furna da Maniçoba & Pinturas \\
\hline 41 & Seridó Oriental & Carnaúba dos Dantas & Furna da Pedra Caída & Pinturas \\
\hline 42 & Seridó Oriental & Carnaúba dos Dantas & Furna da Serra Fechada & Pinturas \\
\hline 43 & Seridó Oriental & Carnaúba dos Dantas & Furna do Borrachinha & Pinturas \\
\hline 44 & Seridó Oriental & Carnaúba dos Dantas & Furna do Cupim & Pinturas \\
\hline 45 & Seridó Oriental & Carnaúba dos Dantas & Furna do Mateus & Pinturas \\
\hline 46 & Seridó Oriental & Carnaúba dos Dantas & Furna do Messias & Pinturas \\
\hline 47 & Seridó Oriental & Carnaúba dos Dantas & Furna do Olho & Pinturas \\
\hline 48 & Seridó Oriental & Carnaúba dos Dantas & Furna do Pau d'arco & Pinturas \\
\hline 49 & Seridó Oriental & Carnaúba dos Dantas & Furna do Pinhão Branco & Pinturas \\
\hline 50 & Seridó Oriental & Carnaúba dos Dantas & Furna dos Caboclos & Pinturas \\
\hline 51 & Seridó Oriental & Carnaúba dos Dantas & Furna dos Veados & Pinturas \\
\hline 52 & Seridó Oriental & Carnaúba dos Dantas & Gruta das Cabras & Pinturas \\
\hline 53 & Seridó Oriental & Carnaúba dos Dantas & Gruta do Criminoso & Pinturas \\
\hline 54 & Seridó Oriental & Carnaúba dos Dantas & Lagoa do Caramungu & Gravuras \\
\hline 55 & Seridó Oriental & Carnaúba dos Dantas & Pedra da Macambira & Pinturas/gravuras \\
\hline 56 & Seridó Oriental & Carnaúba dos Dantas & Pedra da Mão Redonda & Pinturas \\
\hline 57 & Seridó Oriental & Carnaúba dos Dantas & Pedra da Mesa & Gravuras \\
\hline 58 & Seridó Oriental & Carnaúba dos Dantas & Pedra da Unha & Pinturas/gravuras \\
\hline 59 & Seridó Oriental & Carnaúba dos Dantas & Pedra do Alexandre I & Pinturas \\
\hline 60 & Seridó Oriental & Carnaúba dos Dantas & Pedra do Alexandre II & Pinturas \\
\hline 61 & Seridó Oriental & Carnaúba dos Dantas & Pedra do Cavalo & Gravuras \\
\hline 62 & Seridó Oriental & Carnaúba dos Dantas & Pedra dos Furos & Gravuras \\
\hline 63 & Seridó Oriental & Carnaúba dos Dantas & Riacho das Pinturas I & Pinturas/gravuras \\
\hline 64 & Seridó Oriental & Carnaúba dos Dantas & Riacho das Pinturas II & Gravuras \\
\hline 65 & Seridó Oriental & Carnaúba dos Dantas & Serrote das Areias & Pinturas \\
\hline 66 & Seridó Oriental & Carnaúba dos Dantas & Serrote do Reinado I & Pinturas \\
\hline 67 & Seridó Oriental & Carnaúba dos Dantas & Serrote do Reinado II & Pinturas \\
\hline 68 & Seridó Oriental & Carnaúba dos Dantas & Sítio do Caldeirão & Gravuras \\
\hline 69 & Seridó Oriental & Carnaúba dos Dantas & Sítio do Deca & Pinturas/gravuras \\
\hline 70 & Seridó Oriental & Carnaúba dos Dantas & Sítio do Helder & Pinturas \\
\hline 71 & Seridó Oriental & Carnaúba dos Dantas & Sítio do Letreiro & Pinturas/gravuras \\
\hline 72 & Seridó Oriental & Carnaúba dos Dantas & Sítio do Pote I & Gravuras \\
\hline 73 & Seridó Oriental & Carnaúba dos Dantas & Sítio do Pote II (Veado colorido) & Pinturas \\
\hline 74 & Seridó Oriental & Carnaúba dos Dantas & Sítio Grota Funda & Gravuras \\
\hline 75 & Seridó Oriental & Carnaúba dos Dantas & Sítio Riacho do Meio I & Gravuras \\
\hline 76 & Seridó Oriental & Carnaúba dos Dantas & Sítio Riacho do Meio II & Gravuras \\
\hline
\end{tabular}




\begin{tabular}{|c|c|c|c|c|}
\hline $\mathrm{N}^{\mathbf{0}}$ & Microrregião & Município & Sítio Arqueológico & Tipo de registro \\
\hline 77 & Seridó Oriental & Carnaúba dos Dantas & Sítio Riacho do Meio III & Gravuras \\
\hline 78 & Seridó Oriental & Carnaúba dos Dantas & Sítio Volta do Rio & Pinturas \\
\hline 79 & Seridó Oriental & Carnaúba dos Dantas & Talhado da Onça & Pinturas \\
\hline 80 & Seridó Oriental & Carnaúba dos Dantas & Talhado das Pinturas & Pinturas \\
\hline 81 & Seridó Oriental & Carnaúba dos Dantas & Talhado das Pirogas & Pinturas \\
\hline 82 & Seridó Oriental & Carnaúba dos Dantas & Talhado do Gavião & Pinturas \\
\hline 83 & Seridó Oriental & Carnaúba dos Dantas & Talhado do Menalca & Pinturas \\
\hline 84 & Seridó Oriental & Carnaúba dos Dantas & Talhado do Urubu & Pinturas \\
\hline 85 & Seridó Oriental & Carnaúba dos Dantas & Talhado dos Cabeços & Pinturas \\
\hline 86 & Seridó Oriental & Carnaúba dos Dantas & Tanque dos Marimbondos & Gravuras \\
\hline 87 & Seridó Oriental & Carnaúba dos Dantas & Tanquinhos & Gravuras \\
\hline 88 & Seridó Oriental & Carnaúba dos Dantas & Toca do Marmeleiro & Pinturas \\
\hline 89 & Seridó Oriental & Carnaúba dos Dantas & Toca do Tatu & Pinturas \\
\hline 90 & Seridó Oriental & Carnaúba dos Dantas & Xique-Xique I & Pinturas \\
\hline 91 & Seridó Oriental & Carnaúba dos Dantas & Xique-Xique II & Pinturas \\
\hline 92 & Seridó Oriental & Carnaúba dos Dantas & Xique-Xique III & Pinturas \\
\hline 93 & Seridó Oriental & Carnaúba dos Dantas & Xique-Xique IV & Pinturas \\
\hline 94 & Seridó Oriental & Carnaúba dos Dantas & Xique-Xique V & Pinturas \\
\hline 95 & Seridó Oriental & Cruzeta & Fazenda Olho d'água & Gravuras \\
\hline 96 & Seridó Oriental & Currais Novos & Mapirunga I & Pinturas \\
\hline 97 & Seridó Oriental & Currais Novos & Mapirunga II & Pinturas \\
\hline 98 & Seridó Oriental & Currais Novos & Pedra Furada & Pinturas \\
\hline 99 & Seridó Oriental & Currais Novos & Pedra da Lagoa & Pinturas \\
\hline 100 & Seridó Oriental & Currais Novos & Pedra da Trangola & Pinturas \\
\hline 101 & Seridó Oriental & Currais Novos & Pedra do Letreiro & Pinturas \\
\hline 102 & Seridó Oriental & Equador & Sítio do Letreiro & Gravuras \\
\hline 103 & Seridó Oriental & Equador & Sítio do Periquito & Gravuras \\
\hline 104 & Seridó Oriental & Ipueiras & Fazenda Santa Terezinha & Gravuras \\
\hline 105 & Seridó Ocidental & Jardim de Piranhas & Cachoeira do Ferreiro & Gravuras \\
\hline 106 & Seridó Oriental & Jardim do Seridó & Sítio Tanques & Pinturas/Gravuras \\
\hline 107 & Seridó Oriental & Ouro Branco & Pedra Lavrada & Gravuras \\
\hline 108 & Seridó Oriental & Parelhas & Mirador & Pinturas \\
\hline 109 & Seridó Oriental & Parelhas & Pedra do Boqueirão & Pinturas \\
\hline 110 & Seridó Oriental & Parelhas & Pedra do Chinelo & Pinturas \\
\hline 111 & Seridó Oriental & Parelhas & Pedra do Vem-Vem & Pinturas \\
\hline 112 & Seridó Oriental & Parelhas & Toca do Olho d'água das Gatas & Pinturas \\
\hline 113 & Seridó Ocidental & São Fernando & Fazenda Logradouro & Gravuras \\
\hline 114 & Seridó Ocidental & São Fernando & Pai Luís & Gravuras \\
\hline 115 & Seridó Ocidental & São Fernando & Serrote do Lajedo & Gravuras \\
\hline 116 & Seridó Ocidental & São João do Sabugi & Jerusalém I & Gravuras \\
\hline 117 & Seridó Ocidental & São João do Sabugi & Jerusalém II & Gravuras \\
\hline
\end{tabular}




\begin{tabular}{|c|c|c|c|c|}
\hline$N^{\circ}$ & Microrregião & Município & Sítio Arqueológico & Tipo de registro \\
\hline 118 & Seridó Ocidental & São João do Sabugi & Pedra Lavrada & Gravuras \\
\hline 119 & Seridó Ocidental & Serra Negra do Norte & Abernal & Gravuras \\
\hline 120 & Seridó Ocidental & Serra Negra do Norte & Carrapateira I & Gravuras \\
\hline 121 & Seridó Ocidental & Serra Negra do Norte & Fazenda Abernal I & Gravuras \\
\hline 122 & Seridó Ocidental & Serra Negra do Norte & Fazenda Abernal II & Gravuras \\
\hline 123 & Seridó Ocidental & Serra Negra do Norte & Fazenda Dinamarca I & Gravuras \\
\hline 124 & Seridó Ocidental & Serra Negra do Norte & Fazenda Dinamarca II & Gravuras \\
\hline 125 & Seridó Ocidental & Serra Negra do Norte & Fazenda Lagoa da Serra & Gravuras \\
\hline 126 & Seridó Ocidental & Serra Negra do Norte & Fazenda Nova Vida & Gravuras \\
\hline 127 & Seridó Ocidental & Serra Negra do Norte & Fazenda Velame & Gravuras \\
\hline 128 & Seridó Ocidental & Serra Negra do Norte & Logradouro dos Angicos & Gravuras \\
\hline 129 & Seridó Ocidental & Serra Negra do Norte & Riacho das Emas & Gravuras \\
\hline 130 & Seridó Ocidental & Serra Negra do Norte & Umburana & Gravuras \\
\hline 131 & Seridó Ocidental & Serra Negra do Norte & Fazenda Nova Vida & Gravuras \\
\hline 132 & Seridó Ocidental & Serra Negra do Norte & Caibeiras (Brandões) & Gravuras \\
\hline 133 & Seridó Ocidental & Timbaúba dos Batistas & Fazenda Poços I & Gravuras \\
\hline 134 & Seridó Ocidental & Timbaúba dos Batistas & Fazenda Poços II & Gravuras \\
\hline 135 & Seridó Ocidental & Timbaúba dos Batistas & Pintado & Gravuras \\
\hline 136 & Seridó Ocidental & Timbaúba dos Batistas & &
\end{tabular}

